\title{
LA FAUNA PLEISTOCÉNICA: EVIDENCIAS ZOOARQUEOLÓGICAS EN LA MESETA CENTRAL DE SANTA CRUZ, LOS SITIOS DE LA MARÍA
}

\author{
RAFAEL PAUNEROa ${ }^{a}$ CATALINA VALIZA DAVIS ${ }^{b}$, \\ DIEGO RINDEL ${ }^{c} \&$ AUGUSTO TESSONEd
}

\begin{abstract}
RESUMEN
En este trabajo presentamos las evidencias arqueológicas en relación a la extinción de la fauna pleistocénica en Patagonia meridional. Los sitios con componentes pleistocénicos estudiados para esta zona son Cueva Túnel y Casa del Minero 1 ubicados en la localidad arqueológica La María. Estos sitios muestran la contemporaneidad de los primeros pobladores colonizadores de Patagonia con varias especies extinguidas: Hemiauchenia cf. paradoxa, Lama gracilis, Panthera onca mesembrina, Hippidion saldiasi, Megatherium cf. americanum y Arctotherium sp. Además de Lama guanicoe, Rhea sp., Lycalopex griseus y Lycalopex sp., que señalan para esta área diversidad paleoambiental, diferentes funcionalidades de sitios y de patrones de uso de fauna, para la transición Pleistoceno-Holoceno. Asimismo destaca la utilización y consumo de las tres especies de camélidos y la supervivencia de Hippidion saldiasi en ambientes particulares de la meseta. Estos temas son discutidos con la información presente referida a primeras ocupaciones humanas del Cono Sur, en el marco de una creciente superación metodológica que procura integrar diferentes vías de investigación.
\end{abstract}

PALABRAS CLAVE: extinción, fauna pleistocénica, zooarqueología, Patagonia

\section{THE PLEISTOCENE FAUNA: ZOOARCHAEOLOGICAL EVIDENCE IN THE CENTRAL PLATEAU OF SANTA CRUZ, THE SITES OF LA MARÍA}

\section{ABSTRACT}

We present archaeological evidence from the Central Plateau of Santa Cruz regarding the extinction of the Pleistocene fauna. The Pleistocene sites analyzed for this area are Cueva Tunel and Casa del Minero. They are located in La María archaeological locality. These sites show the contemporaneity between

a División Arqueología. Facultad de Ciencias Naturales y Museo. UNLP. Av Paseo del Bosque s/n (1900), La Plata. rpaunero@fcnym.unlp.edu.ar

b CONICET- División Arqueología. Facultad de Ciencias Naturales y Museo. UNLP. Av Paseo del Bosque s/n (1900), La Plata. catavaliza@hotmail.com

CONICET-INAPL. 3 de febrero 1370. CABA drindelarqueo@yahoo.com

d INGEIS-CONICET/UBA. Ciudad Universitaria, 1428 Buenos Aires. atessone@ingeis.uba.ar 
the first settlers of Patagonia and several extinct species: Hemiauchenia cf. paradoxa, Lama gracilis, Panthera onca mesembrina, Hippidion saldiasi, Megatherium americanum cf. and Arctotheirum sp. Present fauna such as Lama guanicoe, Rhea sp., Lycalopex griseus and Lycalopex sp. is also contemporary. All the information points to the fact that southern Patagonia had paleoenvironmental diversity, plurality of sites and different use patterns of wildlife during the Pleistocene-Holocene transition. The use and consumption of the three species of camelids and the survival of Hippidion saldiasi in specific environments of the plateau is also highlighted. These issues are discussed taking into account available information relating to the early human occupation of the Southern Cone, as part of a growing methodological improvement that seeks to integrate different research avenues.

KEY WORDS: extinction, pleistocene fauna, zooarchaeology, Patagonia.

\section{INTRODUCCIÓN}

Varias son las hipótesis que se han planteado para explicar la extinción de la megafauna (Borrero, 1984; Guthrie, 1984; Martin, 1984; Politis et al. 1995; Barnosky et al. 2004). A medida que avanzan las investigaciones se estimula nuevamente a replantearnos las ideas acerca de la extinción de las faunas pleistocénicas y al rol que las poblaciones humanas tuvieron en ella. Podemos visualizar actualmente diferentes explicaciones que sin ser contrapuestas, son integradoras con diferentes acentos. En este sentido, se propone una extinción rápida por sobrematanza en una fase temprana de dispersión de los grupos de cazadoresrecolectores (Alroy, 2001; Haynes, 2006; Martin, 1984; Stedman et al. 2005) o bien, un proceso donde el impacto gradual de la actividad humana, con variedad de posturas, se dio en un contexto de cambio climático y fraccionamiento de los ambientes (Alberdi et al. 2001; Cione et al. 2003, 2009; Paunero, 2010; Politis et al. 1995), entre otras alternativas.

En esta ocasión nos centraremos en presentar las evidencias arqueológicas vinculadas cronológicamente a momentos previos a la desaparición de la mayor parte de dicha megafauna en la Meseta Central de Santa Cruz, considerando los registros obtenidos en los sitios Cueva Túnel y Casa del Minero 1 de La María. Sostenemos que la Meseta Central de Santa Cruz constituye una región importante en la discusión de este proceso, dado que está documentada la ocupación inicial (Cardich et al. 1973; Cardich \& Paunero, 1991-1992; Miotti, 1998, 2004; Miotti \& Salemme, 1999, 2004; Paunero, 2003, 2009; Paunero et al. 2001, 2004, 2005, 2007, 2015; entre otros) acontecida en un marco ambiental cambiante (Alberdi et al. 2001; Borrero, 2001; Miotti 2004). El estudio se centrará en el análisis de las evidencias de utilización humana, principalmente derivado de la información proveniente de estos dos sitios, discutiendo la utilización y consumo de las tres especies de camélidos, así como la supervivencia de Hippidion saldiasi en ambientes particulares de la meseta y el rol que pudo tener el cambio ambiental dentro del proceso de extinción de la megafauna. Asimismo, se presenta una caracterización cronológica del/los eventos de extinción sobre la base de una discusión de las fechas-taxón (Grayson, 1989) y, a su vez, los primeros análisis de isótopos estables sobre fauna extinta y guanaco de Cueva Túnel.

\section{DESCRIPCIÓN DE LOS SITIOS Y MATERIALES}

La localidad arqueológica La María (48 ${ }^{\circ} 24^{\prime}$ Sa $48^{\circ} 35^{\prime}$ S y $68^{\circ} 47^{\prime} \mathrm{O}$ a $68^{\circ} 56^{\prime} \mathrm{O}$ ), se caracteriza por un paisaje con topografía diversa con alturas variables, cañadones, lagunas, zanjones, cuevas, aleros y reparos. Los relevamientos del paisaje, realizados en varias campañas, han permitido ubicar diferentes sectores de la localidad definidos a partir de variables arqueológicas, ambientales y paisajísticas (Paunero, 2000; Paunero et al. 2004, 2005). Fueron determinados 13 sectores, de los que solo describiremos los correspondientes a los sitios tratados, Casa del Minero 1 y Cueva Túnel (Fig. 1).

El sector denominado La María Quebrada aparece enmarcado en un cañadón profundo de paredes verticales de ignimbrita. En la entrada de este sector orientado hacia el oeste y cercano a un colector de aguas de invierno-primavera se 

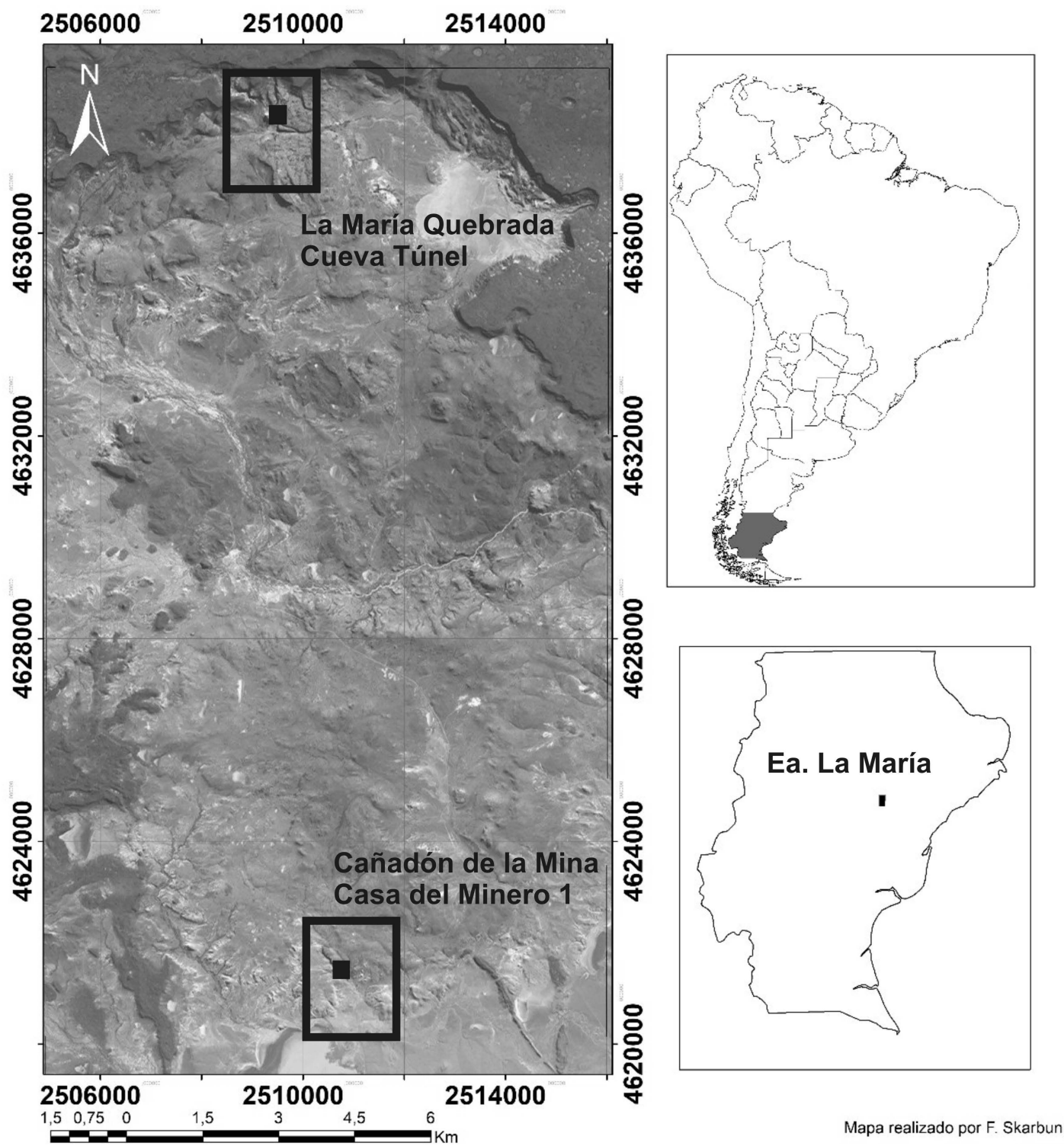

Fig. 1. Mapa Localidad arqueológica La María.

encuentra el sitio Cueva Túnel (CT). Se trata de una cueva con dos vestíbulos tapados por sedimentos que convergen en un umbral. Este sitio fue excavado en sucesivas campañas desde el 2003 al 2010. El sitio presenta una superficie total de 60,6 $\mathrm{m}^{2}$, de los cuales se han excavado $17,245 \mathrm{~m}^{2}$, lo que equivale a un 28,5\% del total (Fig. 2).

La estratigrafía del sitio presenta una potencia total de $260 \mathrm{~cm}$, aunque solo hay material cultural hasta los $120 \mathrm{~cm}$ de profundidad. En este último segmento fueron definidas diez unidades estratigráficas que revelan la presencia de múltiples ocupaciones humanas desde fines del Pleistoceno hasta el Holoceno tardío (Fig. 3). Las unidades 8, 9 y 10 constituyen el denominado componente inferior que corresponde cronológicamente a las ocupaciones ocurridas durante la transición Pleistoceno/Holoceno (Tabla 1).

- Unidad 8: espesor: 8,5-10 cm. Es un sedimento ocre limo-arenoso compacto con presencia de escasos restos arqueológicos y 
carbones dispersos, se obtuvieron dos dataciones de $10.420 \pm 180$ años AP y $10.510 \pm 100$ años AP sobre hueso.

- Unidad 9: espesor: 4-6,5 $\mathrm{cm}$. Se trata de un sedimento ocre limo-arenoso con restos líticos, óseos y carbones dispersos.

- Unidad 10: espesor: 30$32,5 \mathrm{~cm}$. Es un sedimento ocre limo-arenoso con pedregullo, restos líticos y óseos. Se obtuvieron dos fechados: 10.408 \pm 59 años AP sobre fragmento de hueso de camélido y 10.400 \pm 100 años AP sobre falange de Hippidion saldiasi.

El origen de estos sedimentos es principalmente eólico, espélico y antrópico. Se ha propuesto que la sedimentación del componente inferior habría sido un proceso rápido, caracterizado por eventos de vientos intensos, en combinación con la disgregación de roca del techo y la actividad humana (De Porras, 2010; Paunero, 2009). Esto ha provocado que el componente inferior abarque una potencia que en determinados sectores supera los $40 \mathrm{~cm}$. Los fechados radiocarbónicos realizados sobre materiales procedentes de las unidades

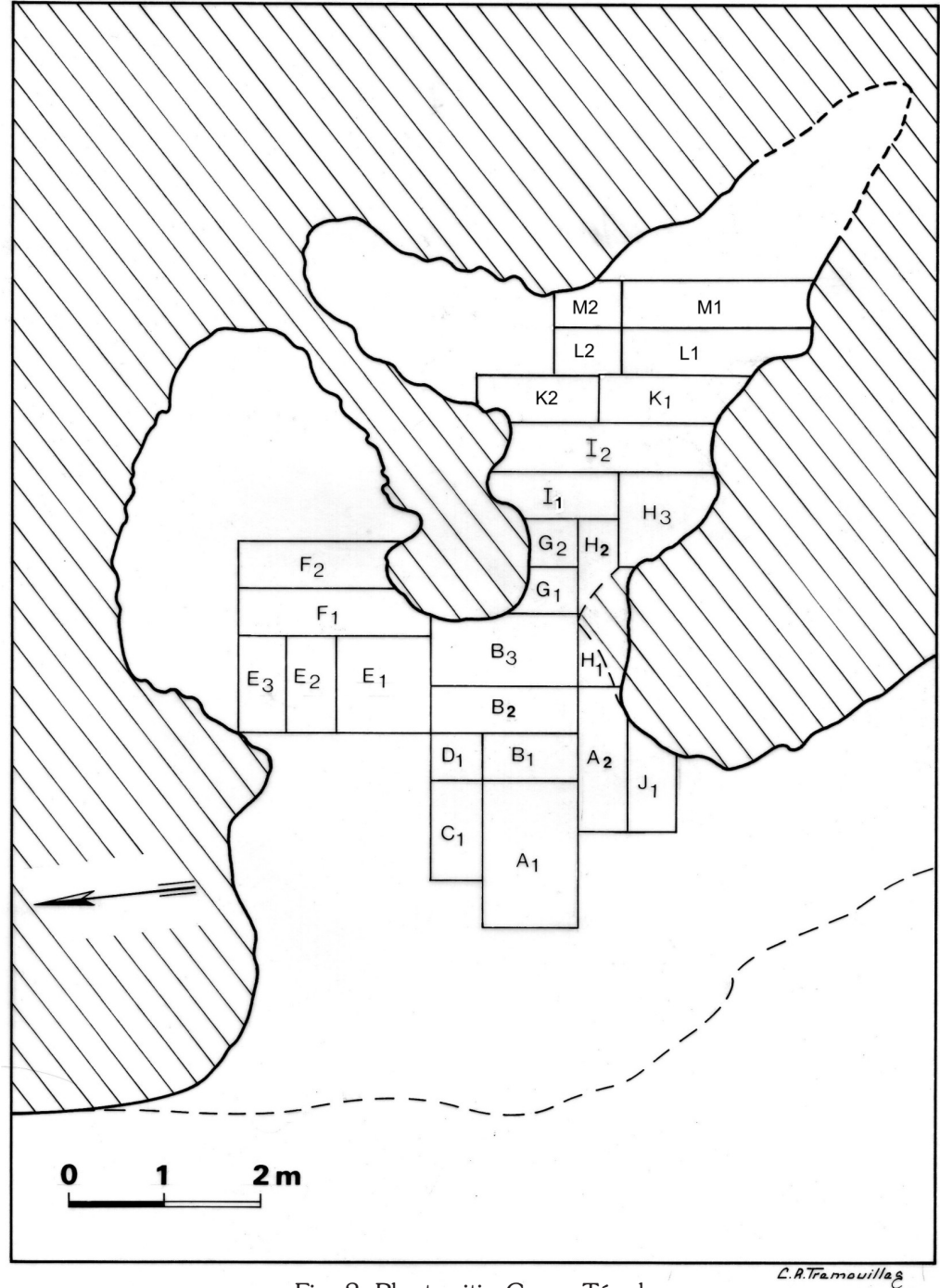

Fig. 2. Planta sitio Cueva Túnel. estratigráficas 8 y 10 indicarían que esta depositación se produjo en un período acotado. A su vez este evento también es visible dada la disposición de los restos arqueológicos; de esta forma, se han remontado fragmentos de artefactos formatizados y elementos óseos dispersos en diferentes cuadrículas y procedentes de distintas profundidades (Frank, 2011).

Por su parte, el sector Cañadón de La Mina incluye al sitio Casa del Minero 1 (CDM1) que se encuentra próxima a una laguna. Este sitio fue trabajado entre los años 2000 y 2005 , siendo excavado $15,32 \mathrm{~m}^{2}$ sobre un total de $55 \mathrm{~m}^{2}$ (22,5\% de la superficie) (Frank, 2012;
Paunero, 2009; Paunero et al. 2005, 2007) (Fig. 4). Esta cueva es un sitio multicomponente con evidencias de ocupaciones humanas que van desde el Pleistoceno final hasta inicios del siglo XX (Paunero et al. 2005, 2007). Las unidades 4 y 3C correspondientes a ocupaciones iniciales poseen datación radiocarbónica (10.999 \pm 55 años AP $/ 10.250 \pm 110$ años AP) (Tabla 2). Estos dos componentes están separados por una clara línea de derrumbe de rocas (Fig. 5):

- Unidad 3: espesor: 10-16 cm. Sedimento ocre areno limoso con piedras de mediano tamaño y fuertemente compactado. Posee evidencias de 


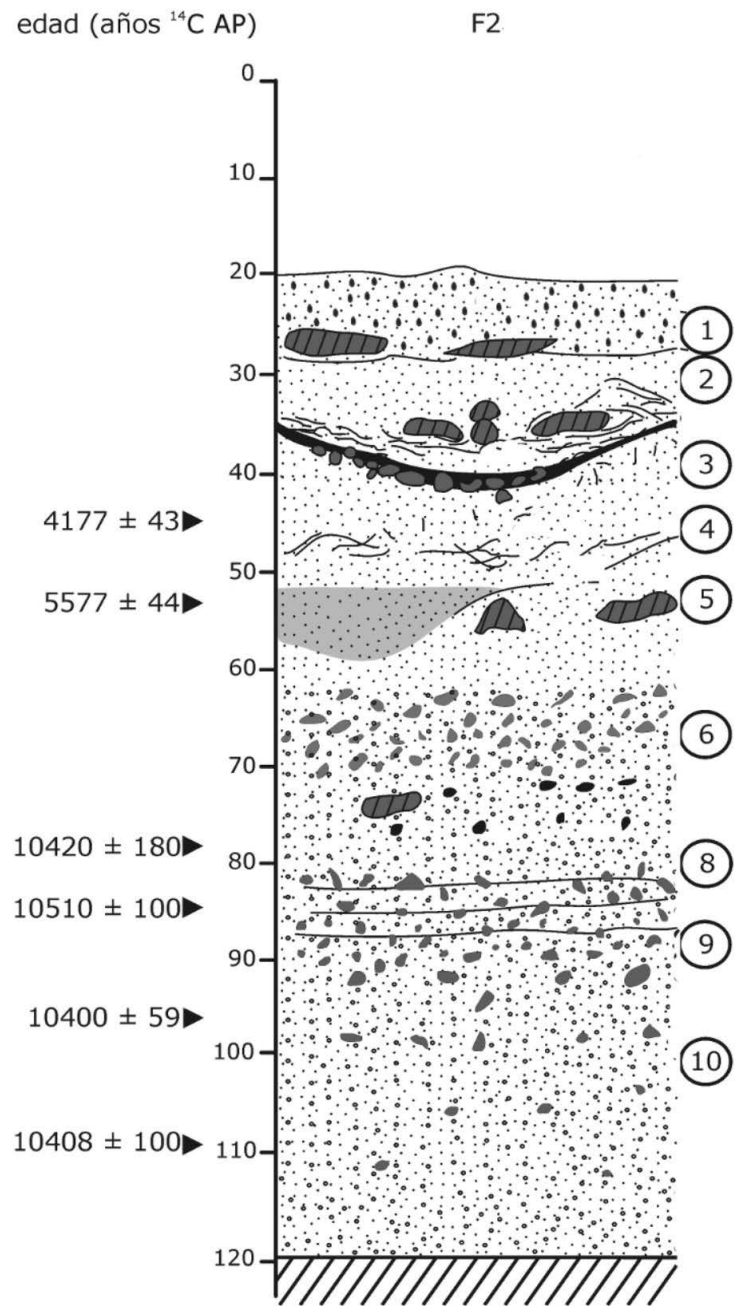

fogones y material arqueológico, ubicado en tres niveles de ocupación: 3A, 3B y 3C (componente pleistocénico). Este último descansa sobre las rocas de derrumbe, sobre el lente estéril o sobre la unidad 4.

- Rocas de derrumbe.

- Lente estéril. Espesor: hasta $5 \mathrm{~cm}$.

- Unidad 4: espesor: 8-20 cm. Sedimento compacto areno-limoso de color ocre claro. Con fogones y contenido cultural.

En lo que refiere a la zooarqueología de los dos sitios, comprobamos que las unidades estratigráficas inferiores, correspondientes a las primeras ocupaciones humanas, están asociadas a fauna extinta. En Cueva Túnel se registró la presencia de Hemiauchenia cf. paradoxa, Lama gracilis, Panthera onca mesembrina, Hippidion
$\therefore$ limo-arenoso con clastos
limo-arenoso con carbones
limo con restos vegetales
limo con sales
ino con fecas de oveja
fogón
Fig. 3. Perfil
(12) rocas estratigráfico sitio Cueva Túnel
(8) niveles arqueológicos
(De Porras, 2010).

Tabla 1. Cronología sitio Cueva Túnel. *Fechados radiocarbónicos. Los fechados fueron calibrados con CALIB 7.0 (Stuiver \& Reimer, 1993), empleando la curva SHCal13.

\begin{tabular}{|c|c|c|c|c|}
\hline Código & Fecha ${ }^{14} \mathrm{C}$ & $\begin{array}{l}\text { Edad calibrada } \\
\text { a } 2 \sigma^{*}\end{array}$ & Material datado & Referencias \\
\hline AA71148 & $10.400 \pm 100$ años AP & $\begin{array}{c}10602-10516(p=0,053531) \\
10501-9870(p=0,946469\end{array}$ & $\begin{array}{l}\text { Segunda falange de } \\
\text { Hippidion saldiasi }\end{array}$ & Paunero, 2009 \\
\hline AA71147 & $10.408 \pm 59$ años AP & $10476-10040$ & Frag. Hueso camélido & Paunero, 2009 \\
\hline LP-1965 & $10.420 \pm 180$ años AP & $\begin{array}{c}10741-9652(p=0,987544) \\
9593-9589(p=0,000642) \\
9583-9547(p=0,00851) \\
9478-9464(p=0,003304)\end{array}$ & Frag. hueso Lama sp. & Paunero, 2009 \\
\hline AA82496 & $10.510 \pm 100$ años AP & $10701-10077$ & Frag. hueso camélido & Paunero, 2009 \\
\hline
\end{tabular}




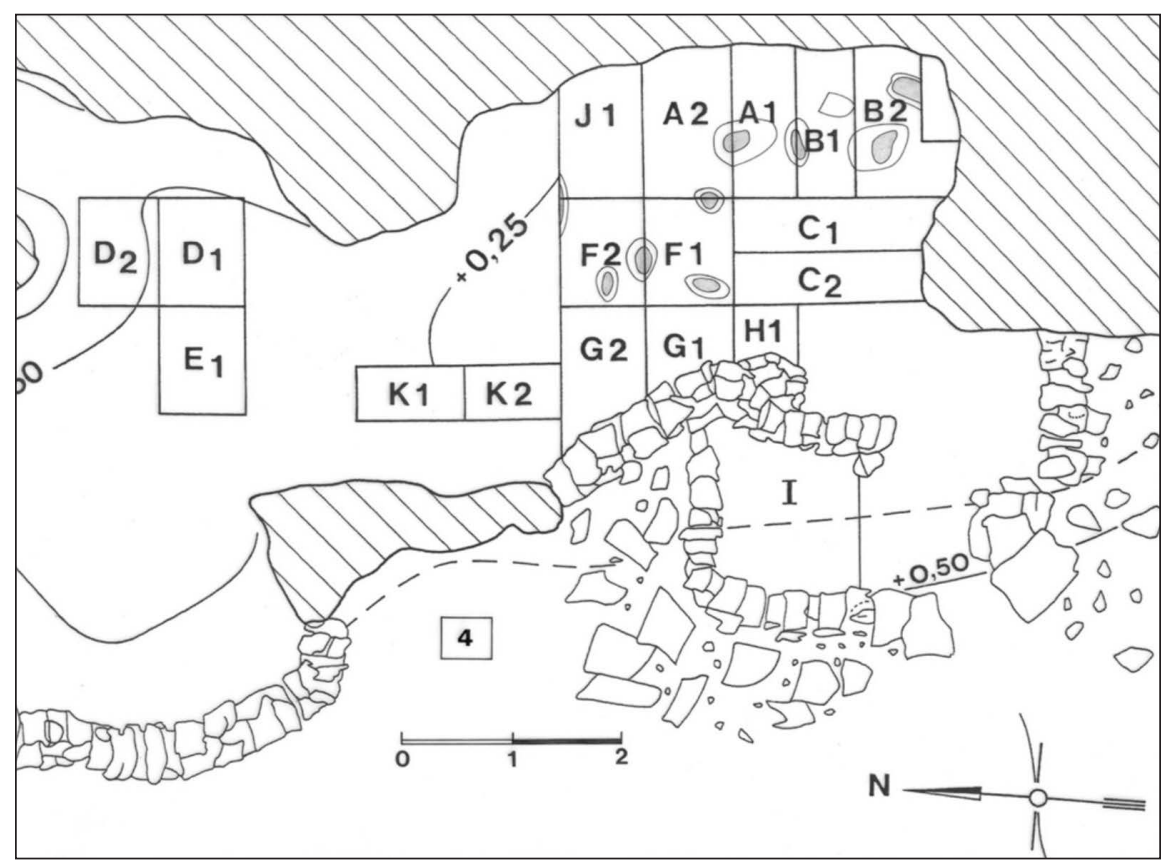

Fig. 4. Planta sitio Casa del Minero 1, Unidad 4.

saldiasi, Megatherium cf. americanum $y$ Arctotherium sp., además de Lama guanicoe, Rhea pennata, Rhea sp.y Lycalopex sp. (Paunero et al. 2015; Valiza Davis et al. 2013). Por su parte, Casa del Minero 1 presenta un conjunto óseo que está conformado por restos de Lama guanicoe y de camélidos extinguidos como Hemiauchenia cf. paradoxa y Lama gracilis, registrándose además restos de Lycalopex griseus, Lycalopex sp. y Rhea sp. (Paunero et al. 2001; 2007; Frank, 2011). La determinación taxonómica de los especímenes óseos de CT fue realizada a partir de la comparación con colecciones de referencia pertenecientes al laboratorio 107 del Anexo Museo de La Plata, a la División de Paleontología del Museo de La Plata y al Instituto Nacional de Antropología y Pensamiento Latinoamericano. Asimismo, se consultaron a diferentes especialistas como los paleontólogos Mariano Bond, Francisco Prevosti y Leopoldo Soibelzon que colaboraron en la determinación de diferentes especies de megafauna y facilitaron especímenes con propósitos comparativos. Dadas las diferencias morfológicas observadas en los especímenes correspondientes a camélidos, además, se evaluó la variabilidad métrica de las primeras falanges

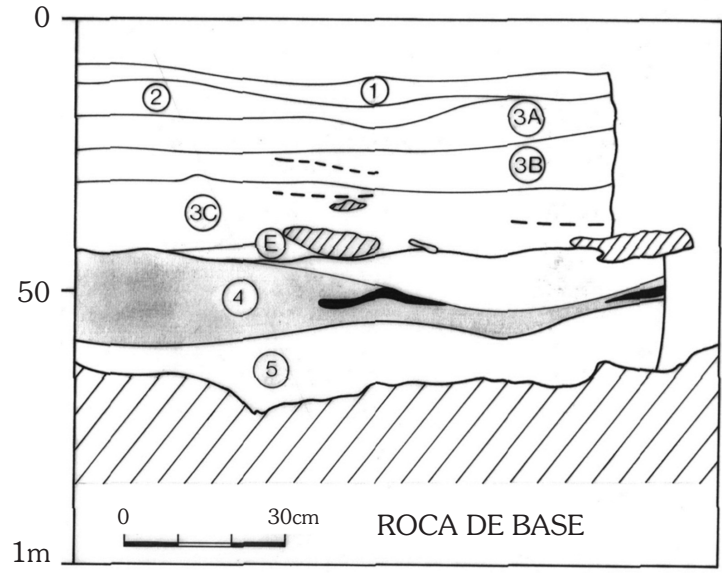

Fig. 5. Perfil estratigráfico sitio Casa del Minero 1.

mediante análisis cuantitativos. Los resultados confirman la presencia de al menos tres especies de camélidos en el sitio Cueva Túnel (Valiza Davis \& Gasco, 2017). Resumiendo, en ambos casos la determinación anatómica y taxonómica de estos conjuntos fue realizada en base a caracteres morfológicos y morfométricos, que han sido complementadas con estudios de ADN para el caso de los camélidos de CDM1 (Metcalf et al. 2014, 2016). Además, los elementos fueron analizados 
Tabla 2. Cronología sitio Casa del Minero 1. *Fechados radiocarbónicos. Los fechados fueron calibrados con CALIB 7.0 (Stuiver \& Reimer, 1993), empleando la curva SHCal13

\begin{tabular}{|c|c|c|c|c|}
\hline Código & Fecha ${ }^{14} \mathrm{C}$ & $\begin{array}{c}\text { Edad calibrada } \\
\text { a } 2 \sigma^{*}\end{array}$ & Material datado & Referencias \\
\hline AA45705 & $10.250 \pm 110$ años AP & $\begin{array}{c}10450-10378 \\
(p=0,045057) \\
10350-9452 \\
(p=0,954943\end{array}$ & Carbón & Paunero, 2000 \\
\hline OXA26128 & $10.750 \pm 45$ años $\mathrm{AP}$ & $\begin{array}{c}10780-10684 \\
(p=0,879393) \\
10651-10613 \\
(p=0,120617)\end{array}$ & Lama gracilis & Metcalf et al. 2016 \\
\hline AA37208 & $10.967 \pm 55$ años $\mathrm{AP}$ & $11003-10755$ & Carbón & Paunero, 2000 \\
\hline AA37207 & $10.999 \pm 55$ años $A P$ & 11031 - 10767 & Carbón & Paunero, 2000 \\
\hline
\end{tabular}

haciendo énfasis en el análisis y cuantificación de indicadores de explotación y uso de recursos por parte de los grupos humanos (Fig. 6 y Tabla 3).

En ambos sitios se ha identificado la utilización de algunas de estas especies por parte de los humanos. Por el momento, los análisis se han centrado especialmente en las especies correspondientes a camélidos, debido a la importancia de los mismos desde los primeros momentos del poblamiento humano en el área (Borrero, 1997, 2009; Miotti, 1998; Miotti \& Salemme, 1999, 2004; entre otros). No descartamos la utilización de otras especies dentro del área meridional de la Patagonia, como Hippidion saldiasi. Si bien sabemos por diversas evidencias que los grupos humanos los cazaban (Alberdi et al. 2001; Alberdi \& Prieto, 2000; Martinic, 1992; Mengoni Goñalons, 1987; Miotti \& Salemme, 1999; Paunero et al. 2005, 2007, 2008), la evidencia actual es aún insuficiente para saber qué incidencia tenían éstos en la dieta de los primeros pobladores de estas estepas (Borrero, 2009). El tipo de restos de Hippidion saldiasi que se encuentran en las cuevas y aleros patagónicos indican que éstos debieron ser transportados como alimento, sea por el hombre u otros carnivoros. De hecho, en la mayoría de los sitios, sólo se encuentran

restos de las partes distales de las extremidades. En Cueva Fell son muchos los restos que están quemados, mientras que en Cueva del Lago Sofía 1 son visibles las huellas de corte (Bird, 1988; Prieto, 1991).

De acuerdo a los datos de procesamiento antrópico para $\mathrm{CT}$, vemos que las tres taxa de camélidos han sido utilizados (Paunero et al. 2015, Valiza Davis et al. 2013), mientras que en CDM1 el procesamiento incluye a Lama guanicoe y

a.

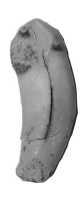

c.

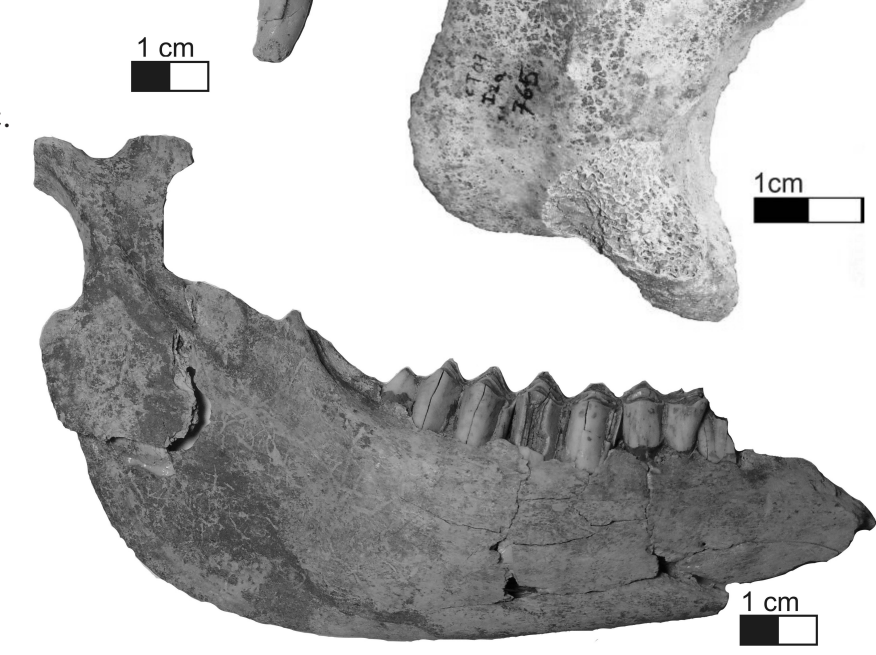

Fig. 6. a. Incisivo superior de Panthera onca mesembrina (CT). b. Escafoides derecho de Megatherium cf. americanum (CT). c. Hemimandibula derecha de Hemiauchenia cf. paradoxa (CDM1). 
Hemiauchenia en la Unidad 4 y sólo a Lama guanicoe en la Unidad 3C (Paunero et al. 2007). La distribución de los diferentes tipos de marcas de procesamiento antrópico se representa de diferentes maneras en $\mathrm{CT}$. En el guanaco predominan las marcas de corte $(\mathrm{N}=25)$, seguidas por las de corte y percusión $(\mathrm{N}=19)$ y finalmente aquellos elementos que presentan sólo percusión $(\mathrm{N}=12)$. En el caso de Lama gracilis, por el contrario, se observa un predominio de evidencias de percusión $(\mathrm{N}=4)$, seguidos por las categorías de corte $(\mathrm{N}=3)$ y corte y percusión $(\mathrm{N}=2)$. Finalmente, sólo se detectaron evidencias de corte en Hemiauchenia $(\mathrm{N}=1)$ (Valiza Davis et al. 2013). Las evidencias de procesamiento de camélidos en CDM1 remiten a un predominio de marcas de corte $(\mathrm{N}=21)$, seguidas de evidencias de percusión $(\mathrm{N}=18)$. Estos estudios requieren aun un análisis en detalle, el que nos permita ver las diferencias en la utilización humana entre las diferentes especies de camélidos. Por otra parte, se han hallado en el componente inferior de CT dos artefactos formatizados elaborados sobre diáfisis de camélido; se trata de un fragmento con punta roma en el extremo y de un punzón doble (Paunero et al. 2010). Además, destaca un fémur de Lama gracilis con marcado perimetral (Paunero et al. 2015), el mismo puede ser el producto de la utilización de insumos provenientes de especies extintas en la elaboración de instrumentos, o bien parte del proceso de la extracción de médula ósea (Hadjuk \& Lezcano, 2005; Muñoz \& Belardi, 1998).

Los análisis de frecuencias de partes esqueletarias indican para estos componentes una mayor representación de elementos de Lama guanicoe. En CT la alta frecuencia corresponde a atlas, pelvis y diáfisis de huesos largos, mientras que en CDM1 se encuentra representada en su mayoría por costillas y falanges (Paunero et al. 2007, 2015). Las altas frecuencias en Lama gracilis en CT están medidas por elementos del cráneo, con una mediana representación de pelvis, húmero y fémur, calcáneo, astrágalo y primera falange. A su vez Lama gracilis en CDM1 se encuentra representada en su mayoría por radiocúbitos, metacarpianos e
Tabla 3. Estructura taxonómica del componente inferior de sitio Cueva Túnel y Casa del Minero 1 (NISP).

\begin{tabular}{|c|c|c|c|}
\hline NISP & CT & \multicolumn{2}{|c|}{$\mathrm{CDM}^{*}$} \\
\hline Unidades & 8-9-10 & $3 c$ & 4 \\
\hline Camélido indet. & - & - & 55 \\
\hline Lama sp. & 20 & 8 & 128 \\
\hline Lama guanicoe & 238 & 13 & 36 \\
\hline Lama gracilis & 37 & 3 & 18 \\
\hline Hemiauchenia paradoxa & 16 & - & 11 \\
\hline Panthera onca mesembrina & 1 & - & - \\
\hline Puma concolor & 10 & - & - \\
\hline Megatherium cf. americanum & 1 & - & - \\
\hline Arctotherium sp. & 1 & - & - \\
\hline Hippidion saldiasi & 2 & - & - \\
\hline Lycalopex griseus & 3 & - & 14 \\
\hline Lycalopex sp. & 4 & - & 12 \\
\hline Zaedyus pichi & 1 & - & - \\
\hline Chloephacta picta & 1 & - & - \\
\hline Rhea pennata & 1 & - & - \\
\hline Rhea sp. & 15 & 11 & 8 \\
\hline Ave indet. & - & 5 & 14 \\
\hline Mamífero grande & 33 & 4 & 67 \\
\hline Roedor indet. & - & 3 & 8 \\
\hline Total & 384 & 47 & 371 \\
\hline
\end{tabular}

Paunero et al. 2007; Frank, 2011.

incisivos, mientras que húmero, cuboides y falanges en mediana frecuencia. Por último, Hemiauchenia cf. paradoxa en CT, presenta una alta frecuencia de fémur, una mediana representación de diáfisis de húmero, radioulna y metapodio distal, mientras que en CDM1 las falanges son las más representadas (Paunero et al. 2007, 2015).

En vinculación a ello, en general los elementos presentan un buen estado de conservación, no superando el estadio 2 de meteorización de Behrensmeyer (1978) para ambos sitios. Del mismo modo los restos de los sitios presentan adherencias correspondientes a depósitos de carbonato de calcio y oxido de manganeso, lo que podría estar indicando ciertas condiciones de humedad (Paunero et al. 2007, 2015). Por otra parte, en CDM1 no se registraron marcas de roedores ni de carnivoros, hecho que sí se evidencia en $\mathrm{CT}$, aunque en bajos porcentajes, dado que solo dos de los huesos asignados a camélido presentan huellas de carnívoro (Paunero et al. 2015). Esto, junto 
con las evidencias mencionadas de procesamiento antrópico, permitiría inferir que el agente responsable de la generación de la mayor parte de ambos conjuntos fueron los seres humanos.

\section{CONTEXTO Y CRONOLOGÍA DE LOS PROCESOS DE EXTINCIÓN EN EL SUR DE PATAGONIA}

Es importante señalar el contexto paleoambiental en el que se desarrolló la ocupación inicial del sur de Patagonia por parte de las poblaciones humanas. En este sentido, es necesario evaluar el impacto de los cambios medioambientales en el proceso de extinción de la fauna pleistocénica, dado que ha sido planteado como una de las principales causas (Alberdi et al. 2001; Borrero, 2009; Cione et al. 2003, 2009; Politis et al. 1995; Paunero, 2010). Contamos para el área de estudio con el importante aporte realizado por De Porras (2010), que trabajó en forma conjunta con nuestro equipo en sucesivas campañas. De esta forma, la reconstrucción paleoambiental inferida a partir del análisis de columnas polínicas obtenidas para la zona de La María, indica un cambio desde condiciones más frías que las actuales hacia mayor temperatura, bajo un régimen de precipitación similar durante el momento de conformación de los contextos arqueológicos (De Porras, 2010). Esto queda evidenciado en las comunidades vegetacionales de La María, dado que entre los 12.000 y 10.250 años AP hay un predominio de una vegetación sub-arbustiva graminosa con predominio de Ephedra frustillata y Nassauvia. Esta vegetación es reemplazada con posterioridad a los 10.250 años AP por una comunidad arbustiva-graminosa de Asteraceae subfamilia Asteroideae, con alta proporción de arbustos enanos y vegetación en cojín (De Porras, 2010). Las diferencias registradas en la vegetación entre CT y CDM1 y áreas aledañas como Los Toldos podrían corresponder a una distribución en mosaico de las comunidades a meso-escala. Es interesante notar que ninguna de estas comunidades presenta análogos actuales a escala local, a meso-escala o a escala regional, pero las proporciones de Ephedra frustillata y Poacea son similares a las registradas en la meseta del Pedrero, a mayor altura sobre el nivel del mar (<900 msnm) y caracterizada por una menor temperatura, mayor amplitud térmica y mayor continentalidad (De Porras, 2010). Esto adquiere sentido si se considera que durante el Pleistoceno la masa continental patagónica duplicaba la proporción actual debido a los bajos niveles del mar (McCulloch \& Davies, 2001; Rabassa \& Clapperton, 1990) lo que habría conllevado un mayor grado de continentalidad en la región de estudio (Miotti, 2004). Un efecto de esto es la mayor heterogeneidad (y posiblemente mayor productividad) en las comunidades de plantas, capaces de sustentar una amplia diversidad de especies animales tales como las registradas en estos sitios.

Esta información puede ser complementada con datos acerca de las características de las especies faunísticas recuperadas en los conjuntos. De esta forma, se encuentran representados en la Meseta Central animales con dietas muy diversas, posiblemente conformadas por consumidores de pastos como los caballos y milodones (Borromei, 2003; De Porras \& Prieto, 2008; Miotti \& Salemme, 1999; Páez et al. 1999; Paunero, 2009). En lo que respecta a los camélidos, estas especies están siendo cuestionadas desde análisis moleculares, donde se pone en juego por ejemplo, la existencia de Lama gracilis para la región Patagónica, señalando así la presencia de Vicugna vicugna, lo que estaría hablando de una mayor extensión espacial de esta especie que la actualidad (Weinstock et al. 2009). En este sentido, bajo la premisa de que Lama gracilis sea un taxón análogo a la vicuña se esperaría para este que en su dieta incluya un alto porcentaje de pastos. Por otra parte, se registran animales con posibles dietas mixtas (incluyen tanto pastos como arbustos), tales como Lama guanicoe, Hemiauchenia cf. paradoxa y Megatherium americanum (Pradeiro et al. 2012). Para comenzar a investigar el problema de la variabilidad de nichos posibles de esta fauna, se procesaron cuatro muestras correspondientes a las capas inferiores del CT. Se obtuvo colágeno en tres muestras, dos correspondientes a fauna extinta (Lama gracilis y Hemiauchenia), y la restante a guanaco. Los parámetros de conservación fueron correctos, con recuperación de colágeno entre el $5 \%$ y el $10 \%$ y con relaciones $\mathrm{C} / \mathrm{N}$ dentro de parámetros normales (2,9 a 3,6), (De Niro, 1985). Estos resultados establecen el carácter primario de los valores alcanzados. 
Los resultados obtenidos para las tres especies presentan una gran similitud, con una dispersión de valores en 0,5 para las dos relaciones isotópicas; entre -18,6 y -19,1 para el $\delta^{13} \mathrm{C}$ y 4,6 y 5,1 para el $\delta^{15} \mathrm{~N}$ (Tabla 4). Los valores $\delta^{13} \mathrm{C}$ señalan una clara asociación con ambientes de vegetación perteneciente a vías fotosintéticas $\mathrm{C}_{3}$, tal como ocurre en la actualidad. De esta manera, los análisis efectuados sobre el material de CT no están indicando diferencias entre los diferentes taxones por más que se esperarían diferencias en función de las dietas posibles (pastoreadores vs. dietas mixtas).

En términos regionales, los valores de Lama guanicoe y gracilis son similares a los obtenidos en Piedra Museo (Tessone et al. 2016), aunque un poco más altos si los comparamos con los disponibles al sur de Patagonia (Prevosti \& Martin, 2013). Estos estudios, por el momento, son muy escasos para poder definir la variabilidad de las especies y los nichos ocupados por los diferentes herbívoros, sobre todo considerando el escenario ambiental cambiante. En este sentido es importante destacar, que los valores aquí publicados serían los primeros de Hemiauchenia cf. paradoxa para Patagonia.

Creemos que la caracterización de este punto es clave para comprender el proceso de extinción de la megafauna, no solo en Patagonia sino también en otras regiones, teniendo en cuenta el impacto de los cambios ambientales en las comunidades vegetales y su vinculación con la cronología de la desaparición de los diferentes taxones. También es importante para comprender el proceso de retracción de los rangos de acción de especies como Rhea americana, que hoy en día no habita el sur de Patagonia (Tonni \& Tambussi, 1986).

Con respecto a la cronología de la extinción, aún faltan más datos de fechas-taxón para poder definir las características del proceso (Borrero, 2009). En este sentido, una pregunta de discusión abierta es si fue un evento único estrechamente constreñido temporalmente o si se trató en cambio, de un proceso escalonado a lo largo del tiempo que afectó diferencialmente a distintas especies. La Tabla 5, que muestra los últimos fechados para cada especie de megafauna en el sur de Patagonia, indica que la extinción de la mayoría de la fauna pleistocénica tuvo lugar en un lapso temporal acotado de 1000 años, entre 11.000 y 10.000 años AP (Metcalf et al. 2016). Sin embargo, sitios como Cerro Bombero están indicando, al menos para el caso del caballo Hippidion saldiasi, una supervivencia en el Holoceno temprano (8.850 \pm 80 años AP) (Paunero, 2010; Paunero et al. 2008). Esto es importante porque la supervivencia de especies de grandes mamíferos ha sido defendida, por ejemplo, también para la región pampeana y planicies de Uruguay (Gutiérrez et al.

Tabla 4. Valores $\delta^{13} \mathrm{C}$ y $\delta^{15} \mathrm{~N}$ en fauna del Pleistoceno de Cueva Túnel.

\begin{tabular}{ccccccc}
\hline AIE & Muestra & Especie & \%Col & $\mathrm{C} / \mathrm{N}$ & $\delta^{13} \mathrm{C}$ & $\delta^{15} \mathrm{~N}$ \\
\hline 33890 & 1248 & Lama gracilis & 10 & 3,3 & $-18,8$ & 5,1 \\
33891 & 804 & Hemiauchenia $c f$. paradoxa & 5 & 3,3 & $-19,1$ & 4,6 \\
33892 & 2070 & Lama guanicoe & 6 & 3,2 & $-18,6$ & 5 \\
\hline
\end{tabular}

Tabla 5. Cronología de la extinción. Fechados tardíos de data-taxón.

\begin{tabular}{ccccc}
\hline Taxón & Data taxón & Sitio & Cod. Lab. & Referencia \\
\hline Hippidion & $8.850 \pm 80$ años AP & Cerro Bombero & LP-1528 & Paunero, 2010 \\
Mylodon & $9.700 \pm 100$ años AP & Cueva Lago Sofía 1 & Gx-31641 & Borrero \& Martín, 2012 \\
Hemiauchenia & $10.430 \pm 100$ años AP & Cueva del Medio & NUTA-1734 & Nami \& Nakamura, 1995 \\
Lama gracilis & $10.630 \pm 70$ años AP & Tres Arroyos & OxA-9246 & Massone, 2004; Massone \& Prieto, 2004 \\
Panthera & $10.840 \pm 60$ años AP & Cueva Sofía 4 & GX-31643 & Martín, 2013 \\
Smilodon & $11.265 \pm 45$ años AP & Cueva del Milodón & OXA-13717 & Barnett et al. 2005 \\
Arctotherium & $10.345 \pm 75$ años AP & Cueva del Puma & Ua-21033 & Martín et al. 2004 \\
\hline
\end{tabular}


2010; Politis \& Gutiérrez, 1998; Prevosti et al. 2011; Suarez \& Santos, 2017; Ubilla et al. 2004) indicando la posibilidad de un proceso que abarque un rango temporal extendido, con diversidad de ecorrefugios y nichos espacialmente distribuidos, lo que conlleva a diferentes implicaciones acerca de los mecanismos causales de la extinción.

\section{DISCUSIÓN Y CONCLUSIONES}

De acuerdo a las diferentes propuestas teóricas, podemos visualizar diversas posturas generales que intentan dilucidar el por qué y el cómo de la extinción diferencial de la fauna, que fue culminando durante la transición PleistocenoHoloceno.

Al respecto creemos que la discusión de los factores causales de la extinción de la megafauna no se agota en estas propuestas previamente reseñadas. En este sentido, la consideración de modelos que incluyen factores únicos, tales como los cambios climático-ambientales (Grayson, 1991; Webb, 2013) y la sobrematanza por parte de cazadores recolectores (Martin \& Klein, 1984) pueden y deben ser complejizados contemplando otras variables que podemos definir genéricamente como ecológicas.

De esta forma, algunos elementos que deben ser explorados involucran aspectos más sutiles e indirectos, como aquellos relacionados con el signo y la magnitud de procesos de degradación ambiental y el impacto que la fragmentación $y / o$ pérdida de hábitats pudo tener en las poblaciones de megafauna (Haynes, 2009). En este sentido, es importante señalar que se han detectado incrementos en el índice de carbón en perfiles muestreados entre 18.500 y 12.600 años calibrados AP (Holz et al. 2016). Estos incrementos, con fechas que coinciden con las primeras evidencias de ocupación humana en Patagonia (Dillehay et al. 2015, Perez et al. 2016), posiblemente están indicando una sinergia entre condiciones climáticas y actividad antrópica (Huber et al. 2004; Holz et al. 2016; Méndez et al. 2016) Asimismo, es necesario discutir la posibilidad de desequilibrios demográficos que resulten en la aparición de cascadas tróficas (Estes et al. 2006, Terborgh \& Estes, 2010), así como la existencia de competencia interespecífica
(Whitney-Smith, 2001), en especial al considerar la integración de nuevos depredadores como los seres humanos a los ambientes finipleistocénicos de Patagonia. Un factor relacionado con este último es la posibilidad de la aparición de procesos vinculados con la sobrecarga de predación (Janzen, 1983; Owen-Smith, 1999). Finalmente, otros factores que han sido planteados para otras partes del mundo son la introducción de especies exóticas (Holdaway, 1999) que en el caso patagónico pareciera descartado (el único candidato es el perro que cada vez está más claro llegó mucho después) y nuevas enfermedades (MacPhee \& Marx, 1997), entre otras. La posibilidad de que una "hiperenfermedad" haya sido un agente causal de la extinción de la megafauna ha sido planteado para especies particulares como el mastodonte (Rothschild \& Laub, 2006) pero no ha sido confirmada en el caso patagónico, pese a que se tomaron muestras en Cueva del Milodón en excelente estado de conservación (Clark et al. 2012a, 2012b).

A partir de estas explicaciones actuales y de viejos interrogantes, muchas preguntas han sido generadas cuando hablamos de extinción, como por ejemplo, por qué se dio la supervivencia de algunos taxones, como el caso del guanaco hasta el presente o incluso la perduración de équidos en el Holoceno y la conservación de Rhea americana en latitudes más altas (Tonni \& Tambussi, 1986). Otra de las inquietudes recurrentes entre los investigadores del tema es el valor del sesgo arqueológico en elecciones $e$ interpretaciones, como en el muestreo en sitios de procesamiento y consumo final, en la conservación diferencial de los materiales óseos, en el costo del acarreo en relación al tamaño corporal desde un conjetural sitio de matanza al campamento, y las diferentes proporciones en el transporte de huesos.

Por otra parte, si hubo una extinción diferencial de taxones con perduración de especies en el Holoceno temprano, resulta pertinente reflexionar sobre las estrategias de subsistencia y las dietas de estas poblaciones humanas en este marco de cambios ambientales.

Consideramos, que más allá de la discusión acerca del uso complementario y/u oportunístico (Nami \& Menegaz, 1991) o logístico de la 
megafauna por parte de los grupos humanos, probablemente no eran presas preferidas (Borrero, 2009). En ese orden, es evidente que hubo una elección temprana del guanaco en la dieta para estos momentos de probable baja densidad de poblaciones humanas. Los cazadoresrecolectores de la transición PleistocenoHoloceno, de acuerdo a la evidencia presentada, cazaban especies gregarias, principalmente guanacos, quizás por características propias de esta especie, por dificultades cinegéticas con las especies mayores $\mathrm{u}$ otras razones que actualmente ignoramos (Miotti et al. 1988). Cabe recordar que esto coincide con las primeras manifestaciones rupestres del área, que tienen en los camélidos a su principal protagonista (Fig. 7) (Paunero et al. 2005; Podestá et al. 2005). Resulta pertinente a estas conclusiones continuar con investigaciones que evidencien como fue el fraccionamiento de los ambientes soporte y si los relictos de estepas herbáceas/pastizales con características de ecorrefugios fueron suficientes para la supervivencia de algunos mamíferos.

Los sitios CT y CDM1 de La María muestran la contemporaneidad de los primeros pobladores colonizadores de Patagonia con varias especies extinguidas: Hemiauchenia paradoxa, Lama gracilis, Panthera onca mesembrina, Hippidion saldiasi, Megatherium cf. americanum y Arctotherium sp., además de Lama guanicoe, Rhea sp., Lycalopex griseus y Lycalopex sp., que señalan para Patagonia meridional diversidad paleoambiental, destacando la utilización y consumo de las tres especies de camélidos que compartían nichos similares. Los datos de Cerro Bombero indican una supervivencia de Hippidion saldiasi hasta el Holoceno temprano, lo cual implica una ampliación del rango temporal concebido hasta el momento para la coexistencia de este taxón con los cazadores-recolectores en Patagonia, llevándolo a casi 2.500 años más. Esta perduración de Hippidion en ambientes particulares de la meseta apoya el modelo que sostiene que el impacto de la actividad humana sobre la megafauna se dio en un

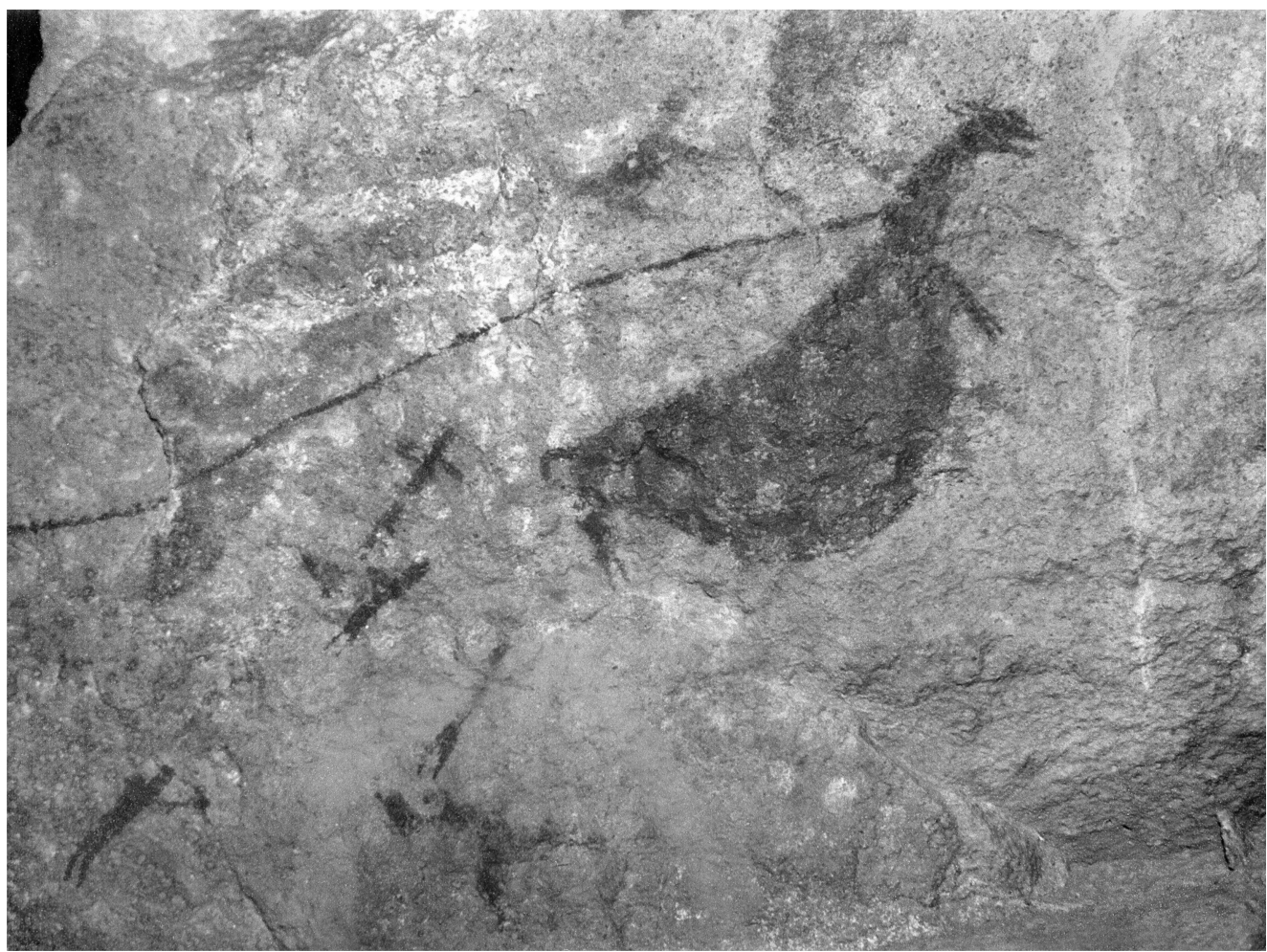

Fig. 7. Guanaco enlazado perseguido por cazadores. Sitio LQM G.

Dimensión: $35 \mathrm{~cm}$ de alto por $52 \mathrm{~cm}$ de ancho. Foto: Favio Vázquez. 
contexto de cambio climático y fraccionamiento de los ambientes.

Es importante resaltar que la Meseta Central muestra algunas diferencias en términos de la utilización de la fauna por parte de las sociedades con respecto a lo que se observa en otras partes de Patagonia. Por ejemplo en Última Esperanza la explotación de la megafauna parece haber sido muy poco intensa, como lo demuestra la evaluación tafonómica de diferentes sitios (Cueva del Milodón, Cueva de los chingues, Cueva del Puma, Cueva del Medio, Cerro Sota, Alero Dos Herraduras) (Bird, 1988; Borrero \& Massone, 1994; Borrero et al. 1991, 1997; Martín et al. 2004, 2011; Martin, 2008; San Román et al. 2000). En este sentido, el análisis presentado es un aporte al análisis de la variabilidad de estrategias implementadas por las primeras poblaciones que habitaron Patagonia meridional. Las ideas acerca de la extinción de los grandes mamíferos y el rol que las poblaciones humanas tuvieron en ella, continua siendo un problema de activa investigación. Para ello hay que implementar en forma conjunta diferentes líneas de estudios: profundizar el trabajo en zonas poco trabajadas como las intermedias, microrregiones, microsectores, probables ecorrefugios, cuencas de drenajes, vertientes y costas, considerando las variedades y particularidades de los paisajes y de los sitios; incrementar los estudios geomorfológicos y palinológicos; ampliar el análisis taxonómico; realizar más fechados ${ }^{14} \mathrm{C}$ data taxón sobre fauna extinta y otros; realizar análisis de isótopos estables y extender los estudios de ADN

\section{AGRADECIMIENTOS}

Agradecemos a la Familia Behm por su invalorable ayuda durante nuestros trabajos en La María. A Francisco Prevosti, Mariano Bond, Leopoldo Soibelzon, José Luis Prado, María Teresa Alberdi por su colaboración en determinaciones taxonómicas y a Marcelo Reguero por facilitar el trabajo en la Div. Paleontología (Museo La Plata). A los evaluadores que contribuyeron a mejorar este trabajo. Finalmente al equipo que participó en la excavación en las sucesivas y trabajosas campañas. Este trabajo fue financiado por CONICET y UNLP.

\section{BIBLIOGRAFÍA}

Alroy, J. (2001). A Multispecies Overkill Simulation of the End Pleistocene Megafaunal Mass Extinction. Science, 292, 1893-1896.

Alberdi, M. T., \& Prieto, A. (2000). Hippidion (Mammalia, Perissodactyla) de las cuevas de las provincias de Magallanes y Tierra del Fuego. Anales del Instituto de la Patagonia, Serie Ciencias Humanas, 28, 147 171.

Alberdi, M. T., Prado, J. L., \& Miotti, L. (2001). Hippidion saldiasi Roth, 1899 (Mammalia, Perissodactyla) at the Piedra Museo Site (Patagonia): their implication for the regional economy and environment. Journal of Archaeological Science, 28, 411-419.

Barnett, R., Barnes, I., Phillips, M. J., Martin, L. D., Haringhton, C. R., Leonard, J. A., \& Cooper, A. L. (2005). Evolution of the extinct sabretooth and the America cheetah-like cat. Current Biology, 15, R589-R590.

Barnosky, A. D., Koch, P. L., Feranec, R. S., Wing, S. L., \& Shabel, A. B. (2004). Assessing the causes of Late Pleistocene extinctions on the continents. Science, 306(5693), 70-75.

Behrensmeyer, A. K. (1978). Taphonomic and ecologic information from bone weathering. Paleobiology, 4(02), 150-162.

Bird, J. (1988). Travels and Archaeology in South Chile. University of Iowa Press. Iowa.

Borrero, L. A. (1984). Pleistocene extinctions in South America. Quarternary of South America and Antarctic Peninsula, 2, 115-126.

Borrero, L. A. (1997). La extinción de la megafauna en la Patagonia. Anales del Instituto de la Patagonia, Serie Ciencias Humanas, 25, 89-102.

Borrero, L. A. (2001). Cambios, continuidades, discontinuidades: discusiones sobre Arqueología Fuego-Patagónica. En E. E. Berberián \& A. E. Nielsen (Eds.), Historia Argentina Prehispánica, 2, (pp. 815-837). Córdoba: Brujas.

Borrero, L. A. (2009). The elusive evidence: the archeological record of the South American extinct megafauna. In G. Haynes (Ed.), American megafaunal extinctions at the end of the Pleistocene (p.145-168). Netherlands: Springer.

Borrero, L. A., \& Martin, F. M. (2012). Ground sloths and humans in southern Fuego-Patagonia: taphonomy and archaeology. World Archaeology, 44(1), 102117. 
Borrero, L., \& Massone, M. (1994). Arqueología de los aleros de Dos Herraduras, Última Esperanza, Chile. Revista del Museo de Historia Natural de San Rafael, 14, 1-4.

Borrero, L., Lanata, L., \& Cardenas, P. (1991). Reestudiando Cuevas: nuevas excavaciones en Ultima Esperanza, Magallanes. Anales del Instituto de la Patagonia, Serie Ciencias Humanas, 20, 101-110.

Borrero, L., Martín, F., \& Prieto, A. (1997). La cueva Lago Sofía 4, Última Esperanza, Chile: Una madriguera de felino del Pleistoceno Tardío. Anales del Instituto de la Patagonia, Serie Ciencias Humanas, 25, 103122.

Borromei, A. M. (2003). Palynology at Piedra Museo locality, Santa Cruz Province, Argentina. In L. Miotti, M. Salemme \& N. Flegenheimer, (Eds.), Where the South Winds Blow (pp. 113-119), Center for the Study of First Americans-Texas A\&M University Press, College Station.

Cardich, A., Cardich, L., \& Hajduk, A. (1973). Secuencia arqueológica y cronología radiocarbónica de la Cueva 3 de Los Toldos (Santa Cruz, Argentina). Relaciones de la Sociedad Argentina de Antropología. VII: 87122.

Cardich, A., \& Paunero, R. S. (1991-1992). Arqueología de la Cueva 2 de Los Toldos (Santa Cruz, Argentina). Anales de Arqueología y Etnología, 46/47, 49-97.

Cione, A. L., Tonni E. P., \& Soibelzon, L. (2003). The Broken Zig-Zag: Late Cenozoic large mammal and tortoise extinction in South America. Revista del Museo Argentino Ciencias Naturales, 5(1), 1-19.

Cione, A. L., Tonni E. P., \& Soibelzon, L. (2009). Did humans cause the late Pleistocene-early Holocene mammalian extinctions in South America in a context of shrinking open areas? En G. Haynes (Ed.), American megafaunal extinctions at the end of the Pleistocene (p. 125-144). Netherlands: Springer.

Clack, A. A., MacPhee, R. D., \& Poinar, H. N. (2012a). Mylodon darwinii DNA sequences from ancient fecal hair shafts. Annals of Anatomy-Anatomischer Anzeiger, 194(1), 26-30.

Clack, A. A., MacPhee, R. D., \& Poinar, H. N. (2012b). Case study: ancient sloth DNA recovered from hairs preserved in paleofeces. En: B. Shapiro \& M. Hofreiter (Eds.), Ancient DNA: Methods and Protocols, Chapter 7 (pp. 51-56). Dordrecht: Humana Press, Springer.

De Niro, M. J. (1985). Postmortem preservation and alteration of in vivo bone collagen isotope ratios in relation to palaeodietary reconstruction. Nature, 317, 806-809.

De Porras, M. E. (2010). Dinámica de la vegetación de la Meseta Central de Santa Cruz durante los últimos 11.000 años: forzantes bióticos y abióticos. Tesis doctoral, Facultad de Ciencias Exactas y Naturales, Universidad Nacional de Mar del Plata, Mar del Plata.

De Porras, M. E., \& Prieto, A. R. (2008). Vegetación de la Meseta Central de Santa Cruz durante las etapas tempranas de Poblamiento. In VII Jornadas de Arqueología de Patagonia, Ushuaia.

Dillehay, T. D., Ocampo, C., Saavedra, J., Sawakuchi, A. O., Vega, R. M., Pino, M.,...Hartmann, G. A. (2015). New archaeological evidence for an early human presence at Monte Verde, Chile. PloS one, 10(11), e0141923

Estes, J. A., De Master, D. P., Doak, D. E., Williams, T. M., \& Brownell Jr., R. L. (2006). Whales, Whaling and ocean ecosystems. University Press, Berkeley.

Frank, A. D. (2011). Tratamiento térmico y manejo del fuego en sociedades cazadoras- recolectoras de la Meseta Central de Santa Cruz. Tesis doctoral, Facultad de Ciencias Naturales y Museo, Universidad Nacional de La Plata, La Plata.

Frank, A. D. (2012). Tratamiento y daño térmico de artefactos líticos en los componentes tempranos del sitio Casa del Minero 1, Santa Cruz, Argentina. Chungara, 44(1), 21-33.

Grayson, D. K. (1989). The chronology of North American latePleistocene extinctions. Journal of Archaeological Science, 16(2), 153-165.

Grayson, D. K. (1991). Late Pleistocene mammalian extinctions in North America: taxonomy, chronology, and explanations. Journal of World Prehistory, 5(3), 193-231.

Guthrie, R. D. (1984). Mosaics, allelochemics and nutrients. An ecological theory of Late Pleistocene Megafaunal extinction. En P. S. Martin y R. G Klein (Ed.), Quaternary Extinctions: A Prehistoric Revolution, (pp. 259-298). University of Arizona Press, Tucson.

Gutiérrez, M. A., Martínez, G. A., Bargo, M. S.m \&. Vizcaíno, S. F. (2010). Supervivencia diferencial de mamíferos de gran tamaño en la Región Pampeana en el Holoceno temprano y su relación con aspectos paleobiológicos. In M. Gutiérrez, M. De Nigris, P. Fernández, M. Giardina, A. Gil, A. Izeta, G. Neme \& H. Yacobaccio (Eds.), Zooarqueología a principios del siglo XXI. Aportes teóricos, metodológicos y casos de estudio, (pp. 231-242). Buenos Aires. 
Hajduk, A., \& Lezcano, M. J. (2005). Un "nuevo-viejo" integrante del elenco de instrumentos óseos de Patagonia: los macha-cadores óseos. Magallania 33, 63-68.

Haynes, G. (2006). A review of some attacks on the overkill hypothesis, with special attention to misrepresentations and doubletalk. Quaternary International, 169(170), 84-94.

Haynes, G. (Ed.). (2009). American megafaunal extinctions at the end of the Pleistocene. Springer Netherlands.

Holdaway, R. N. (1999). Introduced predators and avifaunal extinction in New Zealand. In Extinctions in near time, (pp.189-238). USA: Springer.

Holz, A., Mendez, C., Borrero, L., Prieto, A., Torrejón, F., \& Maldonado, A. (2016). Fires: the main human impact on past environments in Patagonia?, 24(2), 72-73.

Huber, U. M., Markgraf, V., \& Schäbitz, F. (2004). Geographical and temporal trends in Late Quaternary fire histories of Fuego-Patagonia, South America. Quaternary Science Reviews, 23(9), 1079-1097.

Janzen, D. (1983). The Pleistocene hunters had help. American Naturalist, 121, 598-599.

MacPhee, R. D. E., \& Marx, P. A. (1997). The 40,000year plague: humans, hyperdisease, and first-contact extinctions. In S. Goodman \& B. Patterson (Eds.), Natural Change and Human Impact in Madagascar, (pp. 169-217). Washington, D.C.: Smithsonian Institution Press,

Martin, F. (2008) Bone-Crunching Felids at the end of the Pleistocene in Fuego-Patagonia, Chile. Journal of Taphonomy, 6(3), 337-372.

Martin, F. M. (2013). Tafonomía y paleoecología de la transición Pleistoceno-Holoceno en FuegoPatagonia, Interacción entre humanos y carnivoros y su importancia como agentes en la formación del registro fósil. Ediciones de la Universidad de Magallanes, Punta Arenas.

Martín, F. M., Prieto, A., San Román, M., Morello, F., Prevosti, F., Cárdenas, P., \& Borrero, L. A. (2004). Late-Pleistocene Megafauna at Cueva del Puma, Pali-Aike Lava Field, Chile. Current Research in the Pleistocene, 21, 101-103.

Martin, F., San Román, M., \& Morello, F. (2011) Reevaluación tafonómica de la interacción entre cazadoresrecolectores y fauna extinta a fines del Pleistoceno en Última Esperanza, Chile: Modelos de inserción y poblamiento. En A. Borrero \& K. Borrazzo (Eds.), Bosques, montañas y cazadores. Investigaciones arqueológicas en Patagonia Meridional (pp. 105-
126). Editorial Dunken.

Martin, P. S. (1984). Prehistoric Overkill: The Global Model. In P. S. Martin \& R. G. Klein (Eds.), Quaternary Extinctions: A Prehistoric Revolution, (pp. 354403). Tucson: University of Arizona Press.

Martin, P., \& Klein, R. (Eds.). (1984). Quaternary Extinctions: A Prehistoric Revolution. Tucson: University of Arizona Press.

Martinic, M. (1992). Historia de la región magallánica. Punta Arenas: Ediciones de la Universidad de Magallanes.

Massone, M. (2004). Los cazadores después del hielo. Santiago de Chile: Dirección de Bibliotecas, Archivo y Museos: Centro de Investigaciones Diego Barros Arana.

Massone, M., \& Prieto, A. (2004). Evaluación de la modalidad cultural Fell 1 en Magallanes. Chúngara, 36, 303315.

McCulloch, R. D., \& Davies, S. J. (2001). Late-glacial and Holocene palaeoenvironmental change in the central Strait of Magellan, southern Patagonia. Palaeogeography, Palaeoclimatology, Palaeoecology, 173, 143-173.

Méndez, C, De Porras, M, E, Maldonado, A, Reyes, O, Nuevo Delaunay, A., \& García J. L. (2016) Human Effects in Holocene Fire Dynamics of Central Western Patagonia (44。 S, Chile). Frontiers in Ecology and Evolution, 4, 100.

Mengoni Goñalons, G. L. (1987). Modificaciones culturales y animales en los huesos de los niveles inferiores del sitio Tres Arroyos 1 (Tierra del Fuego, Chile). Anales del Instituto de la Patagonia, Serie Ciencias Sociales, 17, 61-66.

Metcalf, J., Barnett, R., Martin, F., Bray, S., Vilstrup, J.T., Orlando, L., Salas-Gismondi, R.,...\& Cooper, A. (2014). Simultaneous late Pleistocene extinctions of megafauna in southern Patagonia, South America. In $12^{\text {da }}$ ICAZ International Conference, San Rafael, Mendoza, Argentina.

Metcalf, J. L., Turney, C., Barnett, R., Martin, F., Bray, S. C., Vilstrup, J. T.,De Nigris, M.,... \& Cooper, A. (2016). Synergistic roles of climate warming and human occupation in Patagonian megafaunal extinctions during the Last Deglaciation. Science Advances, 2(6), 1501682.

Miotti, L. (1998). Zooarqueologia de la Meseta Central y Costa de Santa Cruz. Un enfoque de las estrategias adaptativas aborígenes y los paleoambientes. Revista del Museo de Historia Natural de San Rafael, 
10(1/4), 1-306.

Miotti, L. (2004). La fachada atlántica, como puerta de ingreso alternativa de la colonización humana de América del Sur durante la transición Pleistoceno/ Holoceno. In $2^{\circ}$ Simposio Internacional el Hombre Temprano en América. DAF/INAH. 155-188. México.

Miotti, L., Salemme, M. \& Menegaz, A. (1988). El manejo de los recursos faunísticos durante el Pleistoceno final y Holoceno temprano en Pampa y Patagonia. In Precirculados del IX Congreso Nacional de Arqueología Argentina, 102-118.

Miotti, L., \& Salemme, M. (1999). Biodiversity, Taxonomic Richness and Generalist-Specialists economical systems in Pampa and Patagonia Regions, Southern South America. Quaternary International, 53(54), 53-68.

Miotti, L., \& Salemme, M. (2004). Poblamiento, movilidad y territorios entre las sociedades cazadoras-recolectoras de Patagonia. Complutum, 5, 177-206.

Muñoz, S., \& Belardi, J. B. (1998). El marcado perimetral en los huesos largos de guanaco de Cañadón Leona (Colección Junius Bird): implicaciones arqueofaunísticas para Patagonia Meridional. Anales del Instituto de la Patagonia.

Nami, H., \& Menegaz, A. (1991). Cueva del Medio: aportes para el conocimiento de la diversidad faunística hacia el Pleistoceno-Holoceno en Patagonia austral. Anales del Instituto de la Patagonia, 20, 117-132.

Nami, H. G., \& Nakamura, T. (1995). Cronología radiocarbónica con AMS sobre muestras de hueso procedentes del sitio Cueva del Medio (Última Esperanza, Chile). Anales del Instituto de la Patagonia, 23, 125-133.

Owen-Smith, N. (1999). The interaction of humans, megaherbivores, and habitats in the late Pleistocene extinction event. In R. MacPhee (Ed.), Extinctions in Near Time, (pp.57-69). New York: Springer.

Paez, M. M., Prieto, A. R., \& Mancini, M. V. (1999). Fossil pollen from Los Toldos locality: a record of the Lateglacial transition in the Extra-Andean Patagonia. Quaternary International, 53, 69-75.

Paunero, R. S. (2000). Cueva de la Mesada de La María Quebrada. In L. Miotti, R. S. Paunero, M. C. Salemme y G. R Cattáneo (Eds.), Guía de Campo de la Visita a las Localidades Arqueológicas: La Colonización del Sur de América Durante la Transición Pleistoceno/Holoceno, (pp. 109-113). La Plata.
Paunero R. S. 2003. The presence of a Pleistocene Colonizing Culture in La Maria archaeological locality, Casa del Minero 1. In Miotti, L., Salemme \& M., Flegenheimer (Eds.), Where the South Winds Blow: Ancient Evidence of Paleo South Americans, (pp. 127-132). Edited by Center for the Study of the First Americans (CSFA) and Texas A\&M University Press. College Station.

Paunero, R. S. (2009). La colonización humana de la meseta central de Santa Cruz durante el Pleistoceno final: indicadores arqueológicos, referentes estratigráficos y nuevas evidencias. In M. C. Salemme, F. Santiago, M. Álvarez, E. Piana, M. Vázquez \& M. E. Mansur (Eds.), Arqueología de Patagonia: una mirada desde el último confín (pp. 85-100). Ushuaia: Editorial Utopías.

Paunero R, S. (2010). La extinción de Hippidion saldiasi y su relación con los grupos humanos que colonizaron Patagonia. Nuevos datos provenientes de Cerro Bombero, Santa Cruz. In M. Gutiérrez, M. De Nigris, P. Fernández, M. Giardina, A. Gil, A. Izeta, G. Neme \& H. Yacobaccio (Eds.), Zooarqueología a principios del siglo XXI: Aportes teóricos, metodológicos y casos de estudio, (pp. 297-306). Buenos Aires.

Paunero, R., Albertengo, P., Cueto, M., Dávila, A., Frank, A., Olivera, A., \& Piva, C. (2001). Sitio Casa del Minero 1, localidad arqueológica La María: nuevas evidencias sobre ocupación humana pleistocénica en Santa Cruz. In XIV Congreso Nacional de Arqueología Argentina.

Paunero, R., Cueto, M., Frank, A., Skarbun, F., Ghidini, G., \& Rosales, G. (2004). Comunicación sobre campaña arqueológica 2002 en localidad La María, Santa Cruz. In M. T. Civalero, P. M. Fernández \& A. G. Guráieb (Eds.), Contra viento y marea. Arqueología de la Patagonia, (pp. 797-808). Buenos Aires: Instituto Nacional de Antropología y Pensamiento Latinoamericano - Sociedad Argentina de Antropología.

Paunero, R. S., Frank, A., Skarbun, F., Rosales, G., Zapata, G., Cueto, M., Paunero, M.,... \& Del Giorgio, M. (2005). Arte Rupestre en Estancia La María, Meseta Central de Santa Cruz: Sectorización y contextos arqueológicos. Relaciones de la Sociedad Argentina de Antropología, XXX,147-168.

Paunero, R. S., Frank, A., Skarbun, F., Rosales, G., Cueto, M., Zapata, G., Paunero, M.,... \& Del Giorgio, M. (2007). Investigaciones Arqueológicas en Sitio Casa Del Minero 1, Estancia La María, Meseta Central 
de Santa Cruz. In F. Morello, A. Prieto, M. Martinic \& G. Bahamonde (Eds.), Arqueología de FuegoPatagonia. Levantando piedras, desenterrando huesos... y develando arcanos, (pp. 577-588). Punta Arenas: Ediciones Cequa.

Paunero, R. S., Rosales, G., Prado, J. L., \& Alberdi, M.T. (2008). Cerro Bombero: registro de Hippidion saldiasi Roth, 1899 (Equidae, Perissodactyla) en el Holoceno temprano de Patagonia (Santa Cruz, Argentina). Estudios Geológicos 64(1), 89-98.

Paunero, R. S., Paunero, M. F., \& Ramos, D. (2010). Artefactos óseos en componentes del Pleistoceno final de las localidades La María y Cerro Tres Tetas, Santa Cruz, Argentina. In M. Gutiérrez, M. De Nigris, P. Fernández, M. Giardina, A. Gil, A. Izeta, G. Neme \& H. Yacobaccio (Eds.), Zooarqueología a Principios del Siglo XXI. Aspectos Teóricos, Metodológicos y Casos de Estudio, (pp. 459-466). Ediciones del Espinillo, Buenos Aires.

Paunero, R. S., Frank, A. D., Cueto, M. E., Skarbun, F., \& Valiza Davis, C. (2015). La ocupación pleistocénica de Cueva Túnel, Meseta Central de Santa Cruz: un espacio que reúne actividades en torno al procesamiento primario de presas. Atek $\mathrm{Na}, 149$ 188.

Perez, S. I., Postillone, M. B., Rindel, D., Gobbo, D., Gonzalez, P. N., \& Bernal, V. (2016). Peopling time, spatial occupation and demography of Late Pleistocene-Holocene human population from Patagonia. Quaternary International, 425, 214223.

Praderio, A., Gil, A., \& Forasiepi, A. M. (2012). El registro de Megatherium (Xenarthra, Tardigrada) en Mendoza (Argentina): aspectos taxonómicos, cronológicos y paleoecológicos. Mastozoología Neotropical, 19(2), 163-178.

Prevosti, F. J., Santiago, F., Prates, L., \& Salemme, M. (2011). Constraining the time of extinction of the South American fox Lycalopex avus (Carnivora, Canidae) during the late Holocene. Quaternary International, 245(2), 209-217.

Prevosti, F., \& Martín, F. (2013). Paleoecology of the mammalian predator guild of Southern Patagonia during the latest Pleistocene: ecomorphology, stable isotopes and taphonomy. Quaternary International, 305, 74-84.

Prieto, A. (1991). Cazadores tempranos y tardíos en la Cueva Lago Sofía 1. Anales del Instituto de la Patagonia, Serie Ciencias Sociales, 20, 75-100.
Podestá, M. M., Paunero, R. S., \& Rolandi, D. S. (2005). $\mathrm{El}$ arte rupestre de Argentina indígena: Patagonia. Corpus Americanensium. Argentina V Academia Nacional de la Historia. Union Académique Internationale.

Politis, G. G., Prado, J. L., \& Beukens, R.P. (1995). The human impact in Pleistocene-Holocene exticntions. In E. Johnson (Ed.), South America-The Pampean Case. Ancient Peoples and Landscapes, (p. 187205). Lubbock, Texas: Museum of Texas Tech University.

Politis, G., \& Gutiérrez, M. A. (1998). Gliptodontes y cazadores-recolectores de la región pampeana (Argentina). Latin American Antiquity, 9(2), 111134.

Rabassa, J., \& Clapperton, C. M. (1990). Quaternary Glaciations of the Southern Andes. Quaternary Science Reviews, 9, 123-125.

Rothschild, B. M., \& Laub, R. (2006). Hyperdisease in the late Pleistocene: validation of an early 20th century hypothesis. Naturwissenschaften, 93(11), 557-564.

San Román, M., Morello, F., \& Prieto, A. (2000). Cueva de Los Chingues (Parque Nacional Pali-Aike), Magallanes, Chile. Anales del Instituto de la Patagonia, Serie Ciencias Humanas, 28, 125-143.

Steadman, D. W., Martin, P. S., MacPhee, R. D.,Jull, A. J.,McDonald, H. G., Wood, C. A.,Iturralde-Vinent, M., \& Hodgins G. W. (2005). Asynchronous extinctions of late Quaternary sloths on continents and island. Proceedings of the National Academy of Sciences of the USA, 102, 11763-11768.

Stuiver, M., \& P. J. Reimer. 1993. Extended 14C Data Base and Re-vised CALIB 3.014C Age Calibration Program. Radiocarbon, 35(1), 215-230.

Suárez, R., \& Santos, G. M. (2017). Cazadores recolectores tempranos, supervivencia de fauna del pleistoceno (Equus sp. y Glyptodon sp.) y tecnologia lítica durante el holoceno temprano en la frontera Uruguay-Brasil. Revista de Arqueología, 23(2), 20-39.

Terborgh, J., \& Estes, J. (2010). Trophic cascades: predators, prey and the changing. Dynamics of nature. Island Press.

Tessone, A., Miotti, L., Marchionni, L., Hermo, D., \& Mosquera B. (2016). Variabilidad $\delta 13 \mathrm{C}$ y $\delta 15 \mathrm{~N}$ de la fauna de la transición Pleistoceno/Holoceno en Patagonia austral. Implicancias para el poblamiento humano. In Actas del III Encuentro Latinoamericano de Zooarqueologia, Brasil 2016.

Tonni, E. P., \& Tambussi, C. P. (1986). Las aves del Cenozoico de 
la Republica Argentina. In acta $5^{\circ}$ Congreso argentino de Paleontología y estratigrafía, 131-142. Mendoza.

Ubilla M., Perea, D., Goso Aguilar, C. \& Lorenzo, N. (2004). Late Pleistocene vertebrates from northern Uruguay: tools for biostratigraphic, climatic and environmental reconstruction. Quaternary International, 114, 129-142.

Valiza Davis, C., \& Gasco, A. (2017). Los camélidos en Cueva Túnel (Santa Cruz, Argentina): desde la osteometria hacia una diferenciación de especies. In X Jornadas de Arqueología de la Patagonia, Puerto Madryn.

Valiza Davis, C., Rindel, D., \& Paunero, R. (2013). Los camélidos del pleistoceno final-holoceno temprano en sitio Cueva Túnel, Meseta Central de Santa Cruz: estructura taxonómica, frecuencia de partes esqueletarias, tafonomía y patrones de procesamiento antrópico. In XVIII Congreso Nacional de Arqueología Argentina, La Rioja.

Webb, S. (2013). Corridors to Extinction and the Australian Megafauna. Newnes, Australia.

Weinstock, J., Shapiro, B., Prieto, A., Marín, J. C., González, B. A., Gilbert, M. T. P., \& Willerslev, E. (2009). The Late Pleistocene distribution of vicunas (Vicugna vicugna) and the "extinction" of the gracile llama ("Lama gracilis"): New molecular data. Quaternary Science Reviews, 28(15), 1369-1373.

Whitney-Smith, E. (2001). Second-order predation and Pleistocene extinctions: A system dynamics model. Doctoral dissertation, George Washington University. 